\title{
As fases de pesquisas \\ sobre Computer Assisted Language Learning (CALL) no Brasil: identificação do estado da $\operatorname{arte}^{1}$
}

\author{
Susana Cristina dos Reis \\ Universidade Federal de Santa Maria \\ suzireis@nte.ufsm.br
}

\section{Resumo}

A necessidade do estabelecimento da agenda de pesquisa em Computer Assisted Language Learning (CALL) tem sido foco de investigação de pesquisadores em Linguística Aplicada na última década. Neste trabalho, identifico fases da pesquisa na área de Ensino e Aprendizagem de Inglês mediado por computador, no Brasil, com base na análise dos objetivos e das tendências teóricas das pesquisas publicadas em artigos, dissertações e teses dessa área. Os resultados sugerem que há três fases de pesquisa sobre CALL e que ainda são poucos os pesquisadores da Linguística Aplicada envolvidos em pesquisas sobre CALL no país. Além disso, evidencio que os resultados da teoria e da prática de CALL nas universidades possam ocasionar mudanças curriculares nos Cursos de Letras.

Palavras-chave: CALL; fases das pesquisas; publicações acadêmicas, periódicos acadêmicos brasileiros.

\begin{abstract}
Research in the field of computer assisted language learning (CALL) and teaching has discussed the necessity of defining a research agenda in the area. Because of this, some of these studies have focused on the analysis of research reports to identify the objectives of studies, the methodologies and the themes in order to identify the state of the art. By using a methodology of a research synthesis, this work identifies the Brazilian research stages in the field of CALL based on researches already published. The results suggest three stages of research in Brazil and that there are few Brazilian Applied
\end{abstract}

\footnotetext{
${ }^{1}$ Este artigo é parte da tese investigada no Programa de Pós-Graduação em Letras, na Universidade Federal de Santa Maria.
} 
Linguists producing research and publishing in the field of CALL in our country. Furthermore, it also suggests the necessity of CALL theory and practice to be implemented through academic subjects at Languages courses.

Keywords: CALL; research stages; publication; Brazilian research journals.

\section{Introdução}

No contexto de divulgação do conhecimento, pesquisadores novatos ou experientes buscam, por meio de publicações acadêmicas, identificar o estado da arte de pesquisas como uma maneira de evidenciar os temas em foco durante determinado período de investigação. Em Linguística Aplicada (LA), mais especificamente, na área de Computer Assisted Language Learning $\left(\mathrm{CALL}^{2}\right)$, a atual agenda de pesquisa ainda é foco de discussão tanto em pesquisas brasileiras, quanto em internacionais (LEVY, 2007; 2001; CHAPELLE, 2000; WARSCHAUER, 2004; LEFFA, 2006; REIS, 2010).

No cenário acadêmico brasileiro, as pesquisas realizadas em LA sobre ensino de línguas e tecnologias têm discutido diferentes assuntos, os quais, na maioria das vezes, não são orientados por uma agenda de pesquisa predefinida pela comunidade de pesquisadores dessa área. Isso também fica evidente na afirmação feita por Leffa (2006), em que o autor afirma que "parece haver certa desterritorialização da área" que é caracterizada pela dificuldade de demarcar os limites do que pertence a uma ou outra área de conhecimento, "como se CALL fosse ao mesmo tempo terra de todos e terra de ninguém" (LEFFA, 2006b, p.17).

No contexto acadêmico internacional, alguns autores destacam que estudos sobre linguagem e tecnologias precisam ser aprofundados para o estabelecimento de uma "agenda de pesquisa" (CHAPELLE, 2005; 2000; DEBSKY, 2003; EGBERT; PETRIE, 2005; HUBBARD, 2005; HUH; HU, 2005; LEVY, 2000), pois, de acordo com Chapelle (2000) há uma tendência falaciosa das pesquisas em CALL apenas testarem tecnologias em vez de teorias.

\footnotetext{
${ }^{2}$ No Brasil, alguns pesquisadores referem-se a essa área como Ensino e Aprendizagem mediados por Computador (EAMC).
} 
Na mesma direção, Huh e Hu (2005) enfatizam que pesquisas em CALL precisam ser mais bem relacionadas à teoria de aquisição de línguas estrangeiras. Porém, em estudo mais recente, Stockwell (2007) menciona que o foco dos estudos em CALL deveria ser dirigido à investigação da natureza das tecnologias usadas para o ensino de certas habilidades linguísticas. Para o autor, com base nesses estudos, as teorias que orientam o uso e a escolha dessas tecnologias em sala de aula deveriam ser pesquisadas.

Para entender mais claramente as práticas discursivas realizadas por essa comunidade de pesquisadores, neste artigo problematizo a pesquisa sobre CALL, por meio de uma investigação das fases de pesquisas sobre ensino de línguas e tecnologias, ao analisar publicações acadêmicas sobre esse tema.

Ao observar os temas investigados sobre CALL no Brasil, inicialmente verifiquei em periódicos Qualis A e B da LA se havia publicações sobre essa temática nas revistas selecionadas. Foram encontrados 14 artigos sobre CALL publicados no período de 2005 a 2009. Em vista de mapear os estudos realizados na última década, 1999-2009, considerei as pesquisas resultantes de teses, dissertações, anais de eventos e capítulos de livros, os quais totalizaram 74 estudos.

Os dados obtidos e descritos neste artigo são resultados de pesquisa de doutorado de Reis (2010) e podem contribuir para o estabelecimento da agenda de pesquisa na área de CALL no Brasil. Para tanto, neste artigo, primeiramente, apresento uma proposta de classificação das fases de pesquisas e, nas próximas seções, discuto os principais resultados que contribuíram para essa classificação.

\section{As fases de pesquisas sobre CALL no Brasil}

Ao classificar as pesquisas em CALL no Brasil, busquei, na literatura, referências que discutissem esse tema; no entanto, nenhum artigo foi encontrado, com exceção da pesquisa de Paiva (2008) que propõe um panorama histórico das tecnologias usadas no ensino de línguas, bem como os tipos de atividades (extensionistas, curriculares e extracurriculares) que podem ser realizadas por meio de CALL nas universidades.

Para identificar o que tem sido pesquisado ao longo dos anos, 
as fases propostas neste artigo não levaram em consideração as tecnologias em estudo ou as concepções de linguagem que orientavam as pesquisas descritas nas publicações. Porém, é importante destacar que podem existir outros tópicos que não foram identificados neste estudo simplesmente pela falta de acesso a tais trabalhos. Assim, de acordo com Reis (2010), as pesquisas sobre CALL, publicadas na última década, no Brasil, podem ser divididas em três fases:

a) Fase 1 - Inserção de tecnologias nas aulas de línguas estrangeiras - nesta fase as pesquisas focalizam estes subtópicos: surgimento da internet e uso de computadores na escola; importância do uso de tecnologias no ensino; motivação e autonomia em ambientes virtuais; papel do professor e do aluno no ensino mediado por computador;

b) Fase 2 - Implementação e elaboração de materiais didáticos por meio de tecnologias digitais nesta fase as pesquisas focalizam os seguintes temas: investigação de materiais didáticos para o ensino online; análise de cursos e de softwares; papel do professor em contexto online; "andaimes" para o contexto online de ensino; gêneros emergentes do contexto digital; uso de gêneros digitais na sala de aula de línguas; tarefas de línguas com foco no uso de gêneros digitais; comunidades virtuais; teoria da atividade; objetos de aprendizagem; hipertextos.

c) Fase 3 - Avaliação de atividades de linguagem no contexto digital e de relatos de experiência sobre o ensino mediado por computador nesta fase há foco nos sub-tópicos: gêneros digitais; comunidades virtuais de aprendizagem; (e)Teletandem; atividades; sistemas complexos, hipertextos.

A classificação proposta configura-se em uma primeira tentativa de organizar os temas de interesse dos pesquisadores brasileiros e busca mostrar mais detalhes sobre as pesquisas publicadas em cada período, destacando os resultados que influenciaram (e que influenciam) as investigações da atual agenda de pesquisa.

$\mathrm{Na}$ sequência, discuto cada fase, com ênfase nos principais resultados de cada período. 


\subsection{Fase 1 - Inserção de tecnologias na sala de aula de línguas estrangeiras (LE)}

A fase "Inserção de tecnologias na sala de aula de línguas estrangeiras" enfatizava a inclusão do uso da internet na sala de aula e, nessa época, a discussão centralizou-se em como tecnologias poderiam facilitar a aprendizagem de uma língua estrangeira ao serem inseridas em sala de aula (COLLINS; RAMOS, 1996; BRAGA, 1999A; 1999B; PAIVA, 1999; MOTTA-ROTH et al, 2000).

Diante do entusiasmo tecnológico e das vantagens que tais recursos tinham a oferecer ao ensino da linguagem, na universidade, o foco das discussões eram as implicações que o uso de tecnologias poderia causar nos processos de ensino e de aprendizagem e como elas poderiam ajudar no desenvolvimento da motivação e da autonomia dos participantes envolvidos no processo de aprendizagem de línguas estrangeiras (BRAGA; COSTA, 2000; COLLINS; BRAGA, 2001; MOTTA-ROTH, 2001; PAIVA, 2001A; 1999). Na escola, a preocupação dos professores era em que medida tal ferramenta eletrônica poderia substituí-los em sala de aula. Além disso, havia ainda a resistência ao uso das tecnologias como reportam algumas pesquisas desenvolvidas nesse período (PAIVA, 1999).

Apesar das diferentes opiniões sobre o uso do computador na sala de aula, os resultados das pesquisas nesse período indicaram a necessidade de mudar a forma de ensinar e de apreender quando se faz uso de tecnologias. Portanto, as mudanças deveriam incluir não apenas a inserção de tecnologias na escola, mas também gerar mudanças nos papéis que o professor e o aluno deveriam assumir ao interagir no contexto online.

Ainda na primeira fase, o livro organizado por Paiva (2001A) abordou o tema interação e aprendizagem de línguas em ambiente virtual. Nessa obra, os resultados evidenciaram a importância de o professor inserir, na sala de aula, recursos eletrônicos, com ênfase nas vantagens que tais recursos oferecem aos processos de ensino e de aprendizagem de línguas estrangeiras.

Havia uma preocupação com os benefícios que tanto o professor quanto o aluno teriam ao fazer uso de gêneros eletrônicos ( $e$ mail, chat e páginas pessoais) nas aulas de línguas estrangeiras 
(CHAVES, 2001; FONSECA, 2001; PEREIRA, 2001). Além disso, essas pesquisas apresentavam sugestões sobre como esses gêneros poderiam contribuir para a aquisição da LE e para o desenvolvimento da autonomia do aprendiz (PAIVA, 2001B; MOTTA-ROTH, 2001). Nesses casos, o foco dos estudos era descrever também as diferentes possibilidades de interação que ambientes virtuais possibilitam tanto aos professores quanto aos alunos.

Nessa época, também se iniciaram as investigações em nível de pós-graduação e, de acordo com dados obtidos por meio de entrevista eletrônica, a primeira dissertação defendida sobre ensino mediado por computador foi a de Freire (1992) ${ }^{3}$, na PUC-SP. Nessa pesquisa, o objetivo era investigar as interações existentes entre alunos e professores e conhecer as tarefas computadorizadas, por meio da simulação computadorizada e integrada ao ensino de inglês. Os resultados desse trabalho confirmam o envolvimento do aluno em atividades colaborativas, para solucionar problemas e negociar significados e ainda sugerem que, na ambientação virtual, professores, alunos e software se associam em um processo de regulações mútuas e geram novos papéis que são assumidos por esses participantes.

A fase "Inserção de tecnologias na sala de aula" reflete o impacto que as tecnologias causaram no contexto escolar e como essas tecnologias originaram novos tópicos de discussão e de investigação, visto que a internet gerou novos contextos de interação para a inserção dos participantes do contexto digital.

\subsection{Fase 2 - Elaboração de material didático para o contexto digital e os gêneros emergentes desse contexto}

A segunda fase de pesquisas em CALL enfatiza a elaboração de material didático para o contexto digital e intensifica a investigação sobre os gêneros emergentes desse contexto. Ao analisar as pesquisas publicadas, observo que alguns estudos centraram-se, mais especificamente, na investigação de materiais didáticos e apresentavam certa preocupação com a testagem de cursos e de materiais didáticos

\footnotetext{
3 A dissertação "Interação e simulação computadorizada: uma proposta em CALL", de autoria de Maximina Maria Freire, foi apresentada no Programa de Pós-Graduação em Linguística Aplicada, na PUC-SP, em 1992.
} 
digitais que eram disponibilizados eletronicamente.

Para ilustrar as pesquisas desse período, a tese de Martins Fontes (2002), por exemplo, discutiu as especificidades do meio digital, a interatividade e estruturação hipertextual e documental de um curso de inglês a distância. Nesse estudo, a autora destacou como essas especificidades do meio eletrônico redimensionam, potencializam e criam ações estratégicas que podem ser extremamente relevantes para o processo de aprendizagem de inglês via internet.

Esta preocupação em analisar os materiais já produzidos e em exemplificar o uso de tecnologias no ensino de línguas levou pesquisadores (LEFFA, 2003B; BRAGA, 2003; 2004 A; 2004B; PAIVA, 2003; VETROMILLE-CASTRO, 2003; COLLINS E FERREIRA, 2004; COLLINS, 2003 A; 2003 B; RAMOS E FREIRE, 2004), dentre outros, a investigarem os materiais didáticos digitais produzidos para o ensino de línguas mediado por computador ou oferecidos na modalidade a distância. Nesse período, o foco das pesquisas passou a ser a descrição de materiais de ensino de línguas estrangeiras para a internet e seus possíveis usos em sala de aula.

De acordo com Braga (2004a, p.184-185), “do ponto de vista pedagógico, o computador oferece novos canais de comunicação que facilitam a interação a distância e também a construção de um novo tipo de texto que pode abrir novas perspectivas para a aprendizagem monitorada". Além disso, materiais pedagógicos que exploram as possibilidades do hipertexto são apontados pela pesquisadora como promissores para o estudo independente. O caráter não linear dos recursos hipermídia os diferencia dos materiais impressos. Para a autora, embora "os recursos técnicos ofereçam muitas possibilidades" para a implementação de novas alternativas para os processos de ensino e de aprendizagem de línguas, "não é o meio (eletrônico) que é definidor, mas o uso que fazemos dele é que pode viabilizar mudanças pedagógicas" (idem, p.185).

Vetromille-Castro (2003) sugere que é preciso refletir com cautela sobre como explorar didaticamente recursos eletrônicos em sala de aula. Ao se pensar na elaboração de materiais didáticos para a internet, deve-se considerar o papel do aluno e quais interações ele poderá desenvolver por meio daquele material e não somente na proposta didático-pedagógica que se pretende desenvolver (VETROMILLE-CASTRO, 2003). A inserção do computador, nas 
aulas de LE, não garante a resolução de problemas de ordem pedagógica, simplesmente pelo uso dessas ferramentas no contexto escolar. $\mathrm{O}$ uso de computadores e da internet devem ter um objetivo claro de aprendizagem e isso requer do docente saber avaliar e refletir se a ferramenta é adequada (ou não) à sua proposta de ensino e de aprendizagem.

Ao longo dos anos, é possível observar que as pesquisas em CALL retomam também a discussão de questões que já foram debatidas sobre os processos de ensino e de aprendizagem de línguas, tais como a motivação, a autonomia na aprendizagem, a escolha de materiais adequados e de atividades relevantes ao contexto de ensino. Acredito que essas questões ficaram novamente em evidência porque, nessa fase, muitos materiais passaram a ser disponibilizados eletronicamente e começaram a surgir materiais didáticos digitais que eram simplesmente a transposição de materiais impressos para o meio eletrônico.

Outros estudos da área de CALL começaram a discutir roteiros de avaliação de cursos (FREIRE ET AL., 2004; WISMANN, 2005) e de materiais digitais (FERREIRA, 2004) para que os profissionais que fossem explorar tais recursos em sala de aula refletissem mais profundamente sobre a suas escolhas e sobre o uso de determinados materiais digitais, tais como sites pedagógicos ou atividades de linguagem disponíveis na internet.

A produção de materiais didáticos para a internet gerou ainda a discussão sobre como acontece a prática pedagógica em contextos mediados por computador ou a distância (STAA, 2003; GERALDINI, 2003; CELANI; COLLINS, 2003; REIS, 2004), enfatizando a necessidade de uma nova pedagogia de ensino para esse contexto.

A falta de conhecimento sobre o modo de gerenciar esse novo contexto de aprendizagem e de como o professor pode oferecer "andaimes de conhecimento" ao aluno na interação virtual, são algumas das particularidades que devem ser consideradas pelo professor que pretende trabalhar em uma modalidade de ensino mediada por computador (REIS, 2004; SILVA, 2003). Essas questões também foram abordadas nas pesquisas propostas por Silva (2003), Reis(2004) e por Reis e Silva (2005).

As discussões pedagógicas enfatizadas na segunda fase possibilitaram que o tema sobre o uso de gêneros emergentes do 
contexto digital viesse à tona. Nessa fase, surgiram pesquisas que abordavam questões didático-pedagógicas e o uso de gêneros digitais em sala de aula, bem como a funcionalidade e as características desse uso. O livro organizado por Marcuschi e Xavier (2004) apresentou variadas discussões sobre os gêneros emergentes no contexto das novas tecnologias. Nessa obra, Marcuschi (2004) sugere que vários gêneros textuais surgem juntamente com as novas demandas tecnológicas. No mesmo livro, Araújo (2004) enfatiza que os gêneros do cotidiano estão transmutando para a web, ou seja, o autor discute em sua pesquisa que eventos sociais transmutam-se da esfera social para a esfera eletrônica.

Esses resultados levaram outros pesquisadores a investigar outros gêneros, tais como e-mail, blogs, páginas pessoais e institucionais, bate-papo (PAIVA, 2004; KOMESU, 2004, COLLINS, 2003b). Mais especificamente, pesquisas sobre gêneros digitais sugerem que páginas pessoais e diários virtuais são recursos potenciais para a prática de ensino de línguas, principalmente para o desenvolvimento da comunicação escrita (ABREU, 2005; RUIZ, 2005; KOMESU, 2004; MARSHALL, 2005). Além desses aspectos centrais, nos estudos citados anteriormente, havia também preocupação sobre em que medida era possível descrever os movimentos retóricos desses gêneros digitais, bem como as ações comunicativas realizadas pelos participantes por meio desses gêneros.

Nesse período, Reis(2006) argumenta que no atual contexto sócio-histórico não se pode ignorar que a internet possibilite que os seus usuários façam amplo uso de gêneros digitais no seu dia a dia, pois é possível usar diferentes gêneros para se comunicar com diferentes objetivos. Nesse sentido, a autora (idem) sugere que é responsabilidade do professor orientar o ensino da linguagem com base em gêneros e, assim, possibilitar que os alunos interajam e produzam linguagem por meio de gêneros variados.

A possibilidade de interagir por meio da língua escrita, em contextos eletrônicos, permite aos estudantes aprender a língua, sobre a língua e por meio da língua (MCCARTHY; CARTER, 1994, p.134), pois o aluno tem à sua disposição diferentes contextos de interação e pode, ao interagir, negociar significados e, consequentemente, aplicar seus conhecimentos ao produzir linguagem.

Na segunda fase de pesquisas em CALL, os estudos passaram 
a destacar também princípios teóricos, tais como a teoria sociocultural (VYGOSTKY, 1998), a Teoria da Atividade (LEONTIEV, 1978) e os estudos de gêneros (BAZERMAN, 2005; MEURER, 2005); mais especificamente, as crenças, os valores e as concepções de linguagem de ensino e de aprendizagem.

Essas teorizações citadas, quando aliadas às tecnologias, fundamentam os estudos realizados em CALL (REIS, 2010; 2011) e desafiam os pesquisadores sobre como implementar questões teóricas em situações reais de uso da linguagem, em função do novo meio à disposição para a prática de ensino e para elaborar tarefas no contexto digital.

\subsection{Fase 3 - Avaliação de atividades de línguas e relatos de experiências sobre o ensino no contexto digital}

A terceira fase de pesquisas em CALL focaliza avaliação das atividades didáticas de línguas e dos procedimentos pedagógico adotados em aulas mediadas por tecnologias ou em ambientes virtuais de aprendizagem.

As pesquisas publicadas entre 2005 e 2009 mostram temas que enfatizam, geralmente, o ensino de leitura e de vocabulário em contexto digital (NORA DE SOUZA, 2006; 2007; RIBEIRO, 2006; BASTOS, 2007). Os autores apresentam discussões sobre a autonomia na aprendizagem de línguas por meio de narrativas digitais (PAIVA, 2007A; 2007B; 2006); o papel do computador como tutor ou ferramenta na realização de atividades informatizadas em LI (SOUZA; ALMEIDA, 2007). Também discutem as atividades realizadas em cursos de formação continuada a distância (MICCOLI, 2006), as aplicações da teoria da complexidade na análise de atividades a distância (VETROMILLE-CASTRO, 2008; SILVA, 2008) e a avaliação de atividades de línguas ou de sítios pedagógicos online - a exemplo do teletandem (OLIVEIRA, 2009; ARAÚJO, 2009).

A preocupação em avaliar as atividades realizadas em contexto digital parece ser também foco das discussões de Vetromille-Castro (2008). Para o autor, este é em um momento histórico dos estudos de CALL, no Brasil, em que propostas pedagógicas são colocadas à prova, o que confirma a proposta de terceira fase de pesquisa em CALL, elaborada neste artigo. 
As discussões apresentadas na terceira fase de pesquisa revelam certa preocupação dos pesquisadores não só em avaliar, mas em relatar as experiências já realizadas na área. No entanto, para Vetromille-Castro (2008) as propostas pedagógicas, elaboradas para o contexto digital somente persistirão se a interação social - aspecto necessário para a aprendizagem - se estabelecer, pois a interação se torna um fator essencial para ser observado e trabalhado dentro de Ambientes Virtuais de Aprendizagem (Ava).

Foi verificado inicialmente que as investigações em CALL destacam a necessidade do uso da internet na universidade e nas escolas. Também foi verificada a demanda por desenvolver o letramento digital para investigações que focalizam a produção de material didático digital e a necessidade de formação de professor nesse novo contexto de interação. Então foram propostas alternativas que ajudem pensar na pedagogia online e em estratégias de intervenção pedagógica para a prática de ensino mediado por computador.

Como consequência da inserção de tecnologias no contexto universitário e escolar, chamam atenção as atividades, os gêneros digitais, os objetos de aprendizagem mais adequados ao contexto virtual de interação. Inclusive a avaliação e a implementação dessas tecnologias no sentido de adequar o que foi descoberto de modo a alinhar a teoria e a prática, de acordo com estudos teóricos da linguagem, buscando certezas para poder propor mais generalizações sobre os resultados já obtidos.

Por isso, parece urgente que mais estudos, como o que proponho neste artigo surjam para contribuir para a descrição da agenda de pesquisa em CALL no contexto brasileiro, ou seja, uma forma de identificar tópicos que ainda precisam ser mais bem investigados e merecem mais atenção.

\section{Considerações finais}

As discussões apresentadas neste artigo ajudaram a conhecer os interesses dos pesquisadores brasileiros com relação à área de CALL e o que se têm investigado na última década. Os dados evidenciam que os pesquisadores brasileiros orientam suas pesquisas de acordo com o contexto histórico e cultural em que vivem e pelas 
necessidades pedagógicas que a prática exige.

Conhecer os resultados discutidos e organizá-los tematicamente foi uma maneira de propor uma primeira delimitação da agenda de pesquisa brasileira e verificar nos estudos investigados as tendências teóricas e metodológicas que ainda precisam investigadas e implementadas em sala de aula (REIS, 2010), principalmente os estudos em CALL, na área de inglês como língua estrangeira precisam aprofundar o estudo da linguagem produzida em contextos, gêneros e eventos virtuais realizáveis no ciberespaço.

As contribuições já propostas por meio das pesquisas brasileiras ainda precisam ser tanto teórica quanto pedagogicamente implementadas nos Cursos de Licenciaturas de Letras em nosso país, pois essa área de pesquisa não tem um lugar próprio dentro dos departamentos de ensino nas universidades, ficando as discussões sobre CALL apenas no currículo como disciplinas optativas, de modo que nem sempre é dado o aprofundamento teórico necessário a essa área de investigação.

Acredito que os exemplos apresentados neste artigo dão uma visão geral do que se investiga e dos resultados já obtidos na área que podem contribuir para delimitar o estado da arte. Por outro lado, percebo que as pesquisas descritas nesta pesquisa relatam diferentes experiências sobre o ensino de línguas em contextos mediados por computador e carecem de mais sistematização para ser possível descrever com mais detalhes a agenda de pesquisa na área de CALL.

\section{Referências}

ABREU, Lilia S. O chat educacional: o professor diante desse gênero emergente. In: MARCUSCHI, Luiz A.; XAVIER, Antônio C. S. (Org.). Gêneros textuais: reflexões e ensino. União da Vitória: Kaigangue, 2005, p.87-94.

ARAÚJO, Antônia D. Computadores e ensino de línguas estrangeiras: uma análise de sites instrucionais comunicativos. Linguagem em (Dis)Curso, Tubarão, v.9, n.3, set./dez, 2009. Disponível em: <http://linguagem.unisul.br/paginas/ensino/pos/linguagem/0903/01.ht m>. Acesso em: nov. 2009. 
ARAÚJO, Júlio C. A conversa na web: o estudo da transmutação em um gênero textual. In: MARCUSCHI, Luis A.; XAVIER, Antônio C. (Org.). Hipertexto e gêneros e digitais: novas formas de construção do sentido. Rio de Janeiro: Lucerna, 2004. p. 91-109.

BASTOS, Hélvia P. P. Atividades pedagógicas de cunho instrumental feitas online: teoria e prática. The ESPecialist, São Paulo: EDUC, v.28, n.1, p.17-36, 2007.

BRAGA, Denise B. Práticas letradas digitais: considerações sobre possibilidades de ensino e reflexão social crítica. In: ARAÚJO, Júlio C. (Org.). Internet e ensino: novos gêneros, outros desafios. Rio de Janeiro: Lucerna, 2007. p.181-195.

A comunicação interativa em ambiente hipermídia: as vantagens da hipermodalidade para o aprendizado no meio digital. In: MARCUSCHI, Luiz A.; XAVIER, Antônio C. S. (Org.). Hipertexto e gêneros digitais: novas formas de construção do sentido. Rio de Janeiro: Editora Lucerna, 2004a. p. 144-162.

. Linguagem pedagógica e materiais para aprendizagem independente de leitura na web. In: COLLINS, Heloisa; FERREIRA, Anelise. (Org.). Relatos de experiência de ensino e aprendizagem de línguas na Internet. Campinas: Mercado de Letras, 2004b. p.157-185.

A natureza do hipertexto e suas implicações para a liberdade do leitor e o controle do autor nas interações em ambiente hipermídia. Revista da ANPOLL, São Paulo: USP, v.1, n.15, p. 65-86, 2003.

. A constituição híbrida da escrita na internet: a linguagem nas salas de bate-papo e na construção de hipertextos. Leitura: Teoria e Prática, Campinas, SP, v. 34, p.23-29, 1999a.

. Aprendendo a ler na rede: a construção de material didático para aprendizagem autônoma de leitura em inglês. In: VI Congresso internacional de educação à distância, Rio de Janeiro. Publicação Eletrônica da ABED, São Paulo, 1999b. Disponível em: 
<http://www.abed.org.br/antiga/htdocs/paper_visem/denise_bertoli_bra ga.htm>. Acesso em: mar. 2008.

BRAGA, Denise B.; COSTA, Lúcia A. O computador como instrumento e meio para ensino e aprendizagem de línguas. Trabalhos em Linguística Aplicada, Campinas, SP, v.36, p.61-79, Jul/Dez, 2000.

BAZERMAN, Charles. Gêneros textuais, tipificação e interação. São Paulo: Cortez Editora, 2005.

CELANI, Maria A. A.; COLLINS, Heloisa. Formação contínua de professores em contexto presencial e a distância: respondendo aos desafios. In: BARBARA, Leila; RAMOS, Rosinda C. G. (Org.). Reflexões e ação no ensino-aprendizagem de línguas. Campinas: Mercado de Letras, v.5, p.69-105, 2003.

CHAPELLE, Carol. CALL in the Year 2000: Still in Search of Research Paradigms? Language Learning \& Technology, v.1, n.1, 2000. Disponível em: 〈http://llt.msu.edu/vol1num1/chapelle〉. Acesso em: Jan de 2008.

. Research questions for a CALL Research agenda: A reply to Rafael Salaberry. Language Learning and Technology, v.3, n.1, July 1999.

Disponível em: $<$ http://llt.msu.edu/vol3num1/comment/reply.htm $>$. Acesso em: Jan de 2008 .

.Technology and second language learning: expanding methods and agendas. System, v.32, p. 593-601, 2004. Disponível em: <http://www.elsevier.com/locate/system>. Acesso em: Janeiro de 2008.

CHAVES, Gilda M. M. Interação online: análise de interações em salas de chat. In: PAIVA, Vera Lúcia Menezes Oliveira. (Org.). Interação e aprendizagem em ambiente virtual. Belo Horizonte, MG: Faculdade de Letras, UFMG, 2001.

COLLINS, Heloisa. Design, ensino e aprendizagem online: uma experiência em LE junto a professores de escolas públicas. Revista 
ANPOLL, n.15, p.87-113, jul/dez, 2003a.

. Porque é difícil participar de chats? Revista da ALAB, v. 3, n.2, 2003b.

COLLINS, Heloisa; BRAGA, Denise. Interação e interatividade no ensino de língua estrangeira via redes de comunicação: experiências de dois projetos brasileiros. 2001. Disponível em: $<$ http://www.pucsp.br/ hcollins/publicacoes/interacao_interatividade.h tm> Acesso em: out. 2006.

COLLINS, Heloisa; FERREIRA, Anise. (Org.). Relatos de ensino e aprendizagem de línguas na Internet. Campinas: Mercado de Letras, 2004.

COLLINS, Heloisa; RAMOS, Roxane. G. Interaction in the design of a computer-mediated distance learning course. Direct papers working papers do projeto direct. São Paulo e Liverpool, n. 32, p.1-23, 1996.

DEBSKI, Robert. Analysis of research in CALL (1980-2000) with a reflection on CALL as an academic discipline. ReCALL, v.15, n.2, p.177-188, 2003.

EGBERT, Joy L.; PETRIE, Gina M. (Eds). CALL research perspectives. Mahwah, New Jersey e London: Lawrence Erlbaum Associates, Inc., 2005. 204p.

FERREIRA, Anise. Avaliação de aspectos motivacionais da interface de cursos de inglês baseados em web com webmac (website motivacional analysis checklist). In: COLLINS, Heloisa; FERREIRA, Anise. Relatos de experiência de ensino e de aprendizagem de línguas na Internet. São Paulo: Mercado em Letras, 2004. p. 15-50.

FONSECA, Lorena. Alocação de turnos em salas de chat e em salas de aula. In: PAIVA, Vera L. M. O. (Org.). Interação e aprendizagem em ambiente virtual. Belo Horizonte, MG: Faculdade de Letras, UFMG, 2001. p. 85-99. 
FREIRE, Maximina M. et al. Roteiro para a avaliação de cursos online de idiomas. In: COLLINS, Heloísa; FERREIRA, Anise. (Org.). Relatos de experiência de ensino e aprendizagem de línguas na internet. Campinas: Mercado de Letras, 2004.

GERALDINI, Alexandra F. S. Docência no ambiente digital: ações e reflexão. 2003. Tese. (Doutorado em Linguiística Aplicada). LAEL, Pontifícia Universidade Católica, São Paulo, SP, 2003.

HUBBARD, Philip. A review of subject characteristics in CALL research. Computer Assisted Language Learning, v.18, n.5, p.351-368, 2005.

HUH, Keun; HU, Wen-chi. Criteria for effective CALL research. In: EGBERT, J.; PETRIE,G.M.(eds.). CALL research perspectives. Mahwah, NJ. and London: Lawrence Erlbaum Associates, Inc., 2005. p. 9-21

KOMESU, Fabiana. Blogs e as práticas de escrita sobre si na Internet. In: MARCUSCHI, Luiz A.; XAVIER, Antônio C S.. (Org.). Hipertexto e gêneros digitais: novas formas de construção do sentido. Rio de Janeiro: Lucerna, 2004. p.110-119.

LEFFA, Vilson J. Transdisciplinaridade no ensino de línguas: a perspectiva das teorias da complexidade. Revista Brasileira de Lingüística Aplicada, v. 6, n. 1, p. 27-49, 2006 a.

. A aprendizagem de línguas mediada por computador. In: LEFFA, V. J. (Org.) Pesquisa em lingüística Aplicada: temas e métodos. Pelotas: Educat, 2006b, p. 11-36.

. Análise Automática da resposta do aluno em ambiente virtual. Revista Brasileira de Lingüística Aplicada. Belo Horizonte, v.3, n.2, p. 25 - 40, 2003a.

. Como produzir materiais para o ensino de línguas. In: LEFFA, V.(org). Produção de materiais de ensino: teoria e prática. Pelotas: Educat, 2003b. 
LEONTIEV, Alexis N. Activity, consciousness, and personality. Hillsdale: $\quad$ Prentice-Hall, $1978 . \quad$ Disponível em:<http://marxists.anu.edu.au/archive/leontev/works/1978/index.htm $>$. Acessado em: jul. 2008.

LEVY, Mike. Research and technological innovation in CALL. Innovation in Language Learning and Teaching, v.1, n.1, 2007.

. CALL research: major themes and issues. Ilha do Desterro, n. 41, p. 221-244, jul/dez, Florianópolis, 2001. Disponível em: http://www.periodicos.ufsc.br/index.php/desterro/article/view/7478/68 58. Acesso em: jan. 2008.

Scope, goals and methods in CALL research: questions of coherence and autonomy. ReCALL, v. 12, n. 2, p. 170-195, 2000.

MARCUSCHI, Luiz. A.; XAVIER, Antônio. C. S. (Org.). Hipertexto e gêneros e digitais: novas formas de construção do sentido. Rio de Janeiro: Editora Lucerna, 2004. 195p.

MARSHALL, Débora. Pesquisadores da linguagem no ciberespaço: um estudo sobre o gênero home page pessoal. 2005. Dissertação (Mestrado em Letras) - Universidade Federal de Santa Maria, Santa Maria, RS, 2005.

MARTINS FONTES, Maria C. Aprendizagem de inglês via internet: descobrindo as potencialidades do meio digital. Tese. (Doutorado em Linguíística Aplicada). LAEL, Pontifícia Universidade Católica (PUCSP), São Paulo, SP, 2002.

McCARTHY, Michael; CARTER, Ronald. Language as discourse: perspectives for language teaching. London:Longam Publishing, 1994. 248 p.

MEURER, José L. Gêneros textuais na Análise Crítica de Fairclough. In: MEURER, José L.; BONINI, Adair; MOTTA-ROTH, Désirée. (Orgs.). Gêneros: teorias, métodos, debates. São Paulo: Parábola editorial, 2005. 
MICCOLI, Laura. Tapando buracos em um projeto de formação continuada à distância para professores de LE: avanços apesar da dura realidade. Linguagem \& Ensino, v. 9, n. 1, p.129-158, 2006.

MOTTA-ROTH, Désirée. De receptador de informação a construtor de conhecimento: $\mathrm{O}$ uso de chat no ensino de inglês para formandos de Letras.. In: PAIVA, Vera L. M. (Org.). Interação e aprendizagem em ambiente virtual. Belo Horizonte, MG: FALE-UFMG, p. 230-248, 2001.

MOTTA-ROTH, Désirée et al.; Interação \& motivação em um curso de inglês mediado por computador. Idéias, v. 12, p. 55-59, 2000.

NORA de SOUZA, Patrícia. Princípios para a criação de ambientes hipermidiáticos de aprendizagem de léxico em LE. Estudos AngloAmericanos, Belo Horizonte, MG: Faculdade de Letras da UFMG, n. 29-30, p. 143-162, 2006.

O uso da hipermídia na aprendizagem implícita de vocabulário. The ESPecialist. São Paulo: EDUC, v.28, n.1, p. 59-85, 2007.

OLIVEIRA, Flávia M. A Análise de propostas pedagógicas em portais educacionais para docentes da língua Inglesa: implicações para o ensino e a aprendizagem de línguas no contexto digital. 2009. $244 \mathrm{f}$. Tese (Doutorado em Letras) - Universidade Federal de Santa Maria, 2009.

PAIVA, Vera L. M. O. O uso da tecnologia no ensino de línguas estrangeiras: breve retrospectiva histórica, 2008. Disponível em: http://www.veramenezes.com/techist.pdf Acesso em junho de 2008.

As habilidades orais nas narrativas de aprendizagem de inglês. Trabalhos em Lingüística Aplicada, v. 46, p. 139-304, 2007. Disponível em: <http://www.veramenezes.com/narorais.doc >. Acesso em: abril de 2008. 
. As habilidades orais nas narrativas de aprendizagem. Trabalhos em Lingüística Aplicada, v. 46, n.2, p.165-179, 2007.

. Learning about Language Learning through Multimedia Narratives. Essential Teacher, v. 3, p. 34-37, 2006.

- A pesquisa sobre interação e aprendizagem de línguas mediadas pelo computador. Calidoscópio, v. 3, n. 1, p. 5-12, jan./abr., 2005. Disponível em: <http://www.veramenezes.com/cmc.htm $>$. Acesso em: fev. 2008.

. E-mail: um novo gênero textual. In: MARCUSCHI, Luiz A; XAVIER, Antônio C. S. (Org.). Hipertexto e Gêneros e Digitais: novas formas de construção do sentido. Rio de Janeiro: Editora Lucerna, 2004, p.69-90.

. Feedback in the virtual environment. Psychonology, v.1, n.3, p.257-283, 2003. Disponível em: <http://www.veramenezes.com/feedback.htm>. Acesso em: Junho de 2008.

. Feedback em ambiente virtual. In: LEFFA, Vilson J. (Org.). Interação na aprendizagem das línguas. Pelotas: EDUCAT, 2003. p. 219-254.

. Interação e aprendizagem em ambiente virtual. Belo Horizonte, MG: Faculdade de Letras, UFMG, 2001a.

Aprendendo inglês no ciberespaço. In: PAIVA, Vera. L. M. O. (Org). Interação e aprendizagem em ambiente virtual. Belo Horizonte, MG: Faculdade de Letras, UFMG, p. 270-305, 2001 b.

. Diários online na aprendizagem de língua inglesa mediada por computador. In: MARI, Hugo et al. (Org.). Fundamentos e Dimensões da Análise do Discurso. Belo Horizonte, 1999. p.359-378. Disponível em: <http://www.veramenezes.com/diarios.htm>. Acesso em Maio de 2008. 
PEREIRA, José A. M. Interações online: correções e reparações como processos de reformulação textual nas trocas conversacionais via email.In: PAIVA, Vera L. M. O. (Org.). Interação e aprendizagem em ambiente virtual. Belo Horizonte, MG: Faculdade de Letras, UFMG, 2001.

RAMOS, Rosana C. G.; FREIRE, Maximina M. Curso de leitura instrumental via rede: da preparação à concretização.In: COLLINS, Heloísa; FERREIRA, Anise. (Org.). Relatos de experiência de ensino e aprendizagem de línguas na Internet. Campinas: Mercado de Letras, 2004.

REIS, Susana C. A intervenção pedagógica do professor em contextos diferenciados: a oferta de andaimes na aula de inglês presencial e a distância. 2004. 154f. Dissertação. (Mestrado em Lingüística Aplicada), Instituto de Estudos da Linguagem, Universidade Estadual de Campinas, Campinas, SP, 2004.

Do Discurso à Prática: Textualização de pesquisas sobre o Ensino de Inglês mediado por Computador. Tese. 242f. (Doutorado em Letras). Programa de Pós-Graduação em Letras, Universidade Federal de Santa Maria, Santa Maria, RS, 2010.

- O bate-papo educacional: um gênero potencial para práticas sociais e atividades pedagógicas a distância. Linguagens \& Cidadania, v. 6, p.1-16, 2006. Disponível em: <http://jararaca.ufsm.br/websites/l\&c/download/Artigos/L\&C_2S_06/ SuzanaL\&C2006.pdf >. Acesso em: out. de 2006.

. Pesquisas sobre ensino de inglês mediado por computador: identificando concepções de linguagem nessa área de investigação. Revista de Letras Olho do Boto, v. 2, p. 98-121, 2011.

REIS, Susana C.; SILVA, Valdir. Diferenças e semelhanças entre os padrões de interação online em cursos de duas áreas distintas: Bioquímica da Nutrição e Língua Inglesa. Revista Brasileira de Lingüística Aplicada, Belo Horizonte - MG, v. 5, p.213-236, 2005. 
RIBEIRO, Ana E. Texto e leitura hipertextual: novos produtos, velhos processos. Linguagem \& Ensino, v.9, n.2, p.15-32, jul./dez., 2006.

RUIZ, Eliana M. S. D. Kd o português dk gnt???;-) O blog, a gramática e o professor. In: Revista Brasileira de Lingüística Aplicada, Belo Horizonte: Faculdade de Letras de UFMG, v. 5, n.1, 2005. p.115133.

SILVA, Valdir. Interação social e estratégias lingüísticas no processo de provimento de andaime - scaffolding - em uma disciplina de bioquímica da nutrição oferecida a distância via computador. Dissertação (Mestrado em Lingüística Aplicada), Instituto de Estudos da Linguagem, Universidade Estadual de Campinas, Unicamp, Campinas, S.P, 2003.

A Dinâmica Caleidoscópica do Processo de Aprendizagem Colaborativa no Contexto Virtual: Um estudo na perspectiva da Complexidade/Caos. 2008. Tese de doutorado. Programa de PósGraduação em Estudos Lingüísticos da Faculdade de Letras, Universidade Federal de Minas Gerais, Belo Horizonte, 2008.

SOUZA, Ricardo A.; ALMEIDA, Dilso C. O computador tutor e o computador ferramenta no ensino de línguas: reflexões a partir de dois estudos de caso. Linguagem \& Ensino, v.10, n.1, p.15-45, jan./jun, 2007.

STAA, Betina V. Elaboração e avaliação de design de curso instrumental on-line de escrita acadêmica em inglês. 2003. Tese (Doutorado em Lingüística Aplicada). LAEL, Pontifícia Universidade Católica (PUC-SP), São Paulo, SP, 2003.

STOCKWELL, Glenn. A review of technology choice for teaching language skills and áreas in the CALL literature. ReCALL, v. 19, n. 2, p.105-120, 2007.

VETROMILLE-CASTRO, Rafael. O professor como facilitador virtual: considerações teórico-práticas sobre a produção de materiais para aprendizagem via web ou mediada por computador. In: LEFFA, 
Vilson J. (Orgs.). Produção de materiais de ensino: teoria e prática. Pelotas: Educat, 2003.

- Considerações sobre grupos em ambientes virtuais de aprendizagem como sistemas complexos. Revista Brasileira de Lingüística Aplicada. v. 8, n.1, 2008.

VYGOSTKY, Lev V. A formação social da mente. Tradução de José Cipolla Neto. 6. ed. São Paulo: Martins Fontes, 1998.

WARSCHAUER, Mark. Technological change and the future of CALL. In: FOTOS, S.; BROWN, C. (Eds.). New Perspectives on CALL for second and foreign language classroom. Mahwah, NJ: Lawrence Erlbaum Associates, 2004. p. 15-25.

WISSMANN, Liane D. M. Propósitos educacionais no meio on-line: O caso dos cursos de inglês gratuitos. 2005. Dissertação (Mestrado em Letras) - Universidade Federal de Santa Maria, 2005.

Recebido em: 31/01/2012 Aceito em: $\quad 21 / 11 / 2012$

Title: Brazilian research stages in Computer Assisted Language Learning: the state of the art 